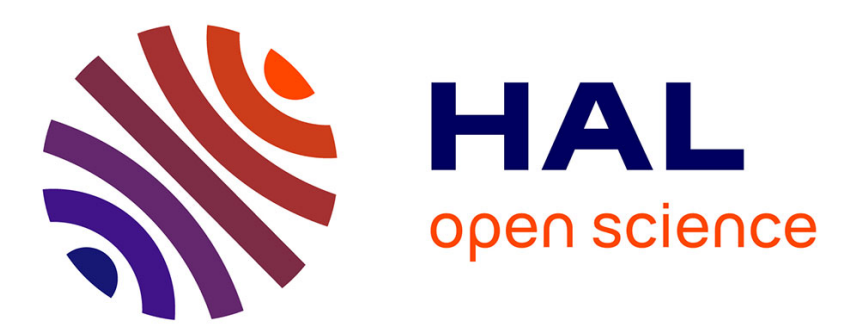

\title{
Fragmentation by high velocity impact on a target: a material grindability test
}

Olivier Lecoq, N Chouteau, M Mebtoul, Jf Large, P Guigon

\section{To cite this version:}

Olivier Lecoq, N Chouteau, M Mebtoul, Jf Large, P Guigon. Fragmentation by high velocity impact on a target: a material grindability test. Powder Technology, 2003, 133 (1-3), pp.113-124. 10.1016/S0032-5910(03)00085-8 . hal-01697284

\section{HAL Id: hal-01697284 \\ https://hal.science/hal-01697284}

Submitted on 6 Nov 2019

HAL is a multi-disciplinary open access archive for the deposit and dissemination of scientific research documents, whether they are published or not. The documents may come from teaching and research institutions in France or abroad, or from public or private research centers.
L'archive ouverte pluridisciplinaire HAL, est destinée au dépôt et à la diffusion de documents scientifiques de niveau recherche, publiés ou non, émanant des établissements d'enseignement et de recherche français ou étrangers, des laboratoires publics ou privés. 


\title{
Fragmentation by high velocity impact on a target: a material grindability test
}

\author{
O. Lecoq ${ }^{\mathrm{a}, *}$, N. Chouteau ${ }^{\mathrm{a}}$, M. Mebtoul ${ }^{\mathrm{a}}$, J.-F. Large ${ }^{\mathrm{a}}$, P. Guigon ${ }^{\mathrm{b}}$ \\ ${ }^{a}$ Laboratoire de Génie des Procédés des Solides Divisés, Ecole des Mines d'Albi, UMR 2392, 81013 Albi CT Cedex 09, France \\ ${ }^{\mathrm{b}}$ Division Technologie Poudres et Suspensions, Département de Génie Chimique, Université de Technologie de Compiègne, BP 20.529, \\ 60205 Compiègne Cedex, France
}

\begin{abstract}
An experimental test rig for the study of impact in an air-jet mill (up to $500 \mathrm{~m} \mathrm{~s}^{-1}$ ) allows the evaluation of the relationship between the impact energy and the fineness of the impacted solids. In single impact tests, so far, three types of behaviour are found: brittle (for glass, sand, polyamide and $\mathrm{NaCl}$ ), "complex" (for $\mathrm{Al}(\mathrm{OH})_{3}$ ) and ductile (for PMMA). A classification is obtained from the definition of grindability parameters. A multi-impact study reveals the non-equivalence between multiple impact and single impact: a solid is not broken similarly if a given total energy is provided in one or several impacts.
\end{abstract}

Keywords: Air-jet mill; Fragmentation; Impact; Grindability test; Powder

\section{Introduction}

Comminution is a very inefficient process: it consumes large amounts of energy. In jet mills, less than $5 \%$ of the provided energy is used for effective fracture, that is, for creation of new surfaces [1]. The development of more energy-efficient processing implies a better fundamental understanding of the various mechanisms involved in the fragmentation of the particles. A test for impact has been developed in order to improve that knowledge. It enables the evaluation of the influence of the operating conditions (impact energy, target material, incident angle, etc.) on the behaviour at impact and the determination of the grindability parameters.

\section{Experimental methods}

\subsection{Equipment}

An experimental air-jet mill (see Fig. 1) is designed to study the fracture of particles accelerated in a jet of air and

\footnotetext{
* Corresponding author. Tel.: +33-5-63-49-30-69; fax: +33-5-63-49$30-25$.

E-mail address: lecoq@enstimac.fr (O. Lecoq).
}

impacting on a target [2]. It includes an air-solid mixing unit, an accelerating supersonic nozzle and a grinding chamber containing the target. The target is a $60-\mathrm{mm}$ diameter silicon carbide disk, $10-\mathrm{mm}$ thick. The adjustable distance between the exit of the nozzle and the target is set at $55 \mathrm{~mm}$. The impact angle between the jet and the target is set at $90^{\circ}$. The jet is a cone of about $1.5^{\circ}$. After impact, the debris are recovered in an air-solid separation section composed of two cyclones and a filter bag.

The solid flow rate is determined from the continuous weighing of the bottom fraction of the first cyclone. The experiments are conducted using very dilute jets having a solid to air flow rate ratio $\mu=W_{\mathrm{s}} / W_{\mathrm{j}}$ of less than 0.1 so as to minimise particle-particle interactions in the jet, in the nozzle and on impact. Under these conditions, the experiments are comparable with single particle impacts.

The kinetic energy supplied to the solid is determined from the velocity of the particles which is measured by two techniques (see Fig. 2): an optical correlation method (vector optical fibre probe [3]) and by video recording using a high shutter speed video camera. In the second technique, the velocities are determined from the measurement of the length of the traces of the particles that are illuminated in a laser sheet, knowing the shutter speed of the camera (varying from 1 to $5000 \mu \mathrm{s}$ ). This equipment allows experiments at velocities from 5 to $500 \mathrm{~m} \mathrm{~s}^{-1}$. 


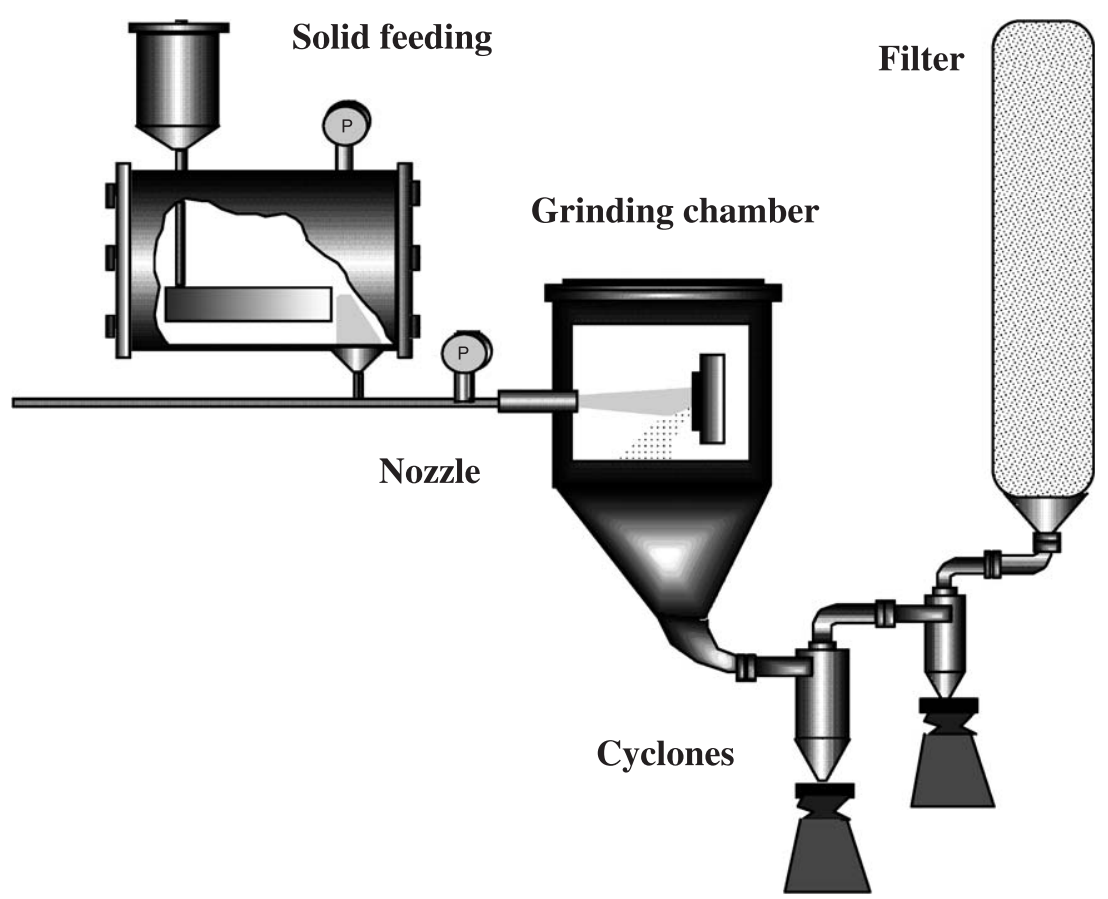

Fig. 1. Experimental single jet apparatus.

\subsection{Methodology}

The experimental parameters are the air flow rate $W_{\mathrm{j}}$, the flow rate of the solid $W_{\mathrm{s}}$ and the nature of the solid. The particle size distribution of each sample of powder is measured before and after impact by sieving (standard NFX 11-501 1970). Scanning electron microscope (SEM) pictures provide for the morphology of the grains before and after impact.

The methodology consists in following the evolution of the particle size distributions, deriving changes in fineness criteria and morphology with the impact velocity $V_{\mathrm{s}}$ or the specific kinetic energy $E_{\mathrm{s}}$ (e.g. $\mathrm{kJ} \mathrm{kg}^{-1}$ ).
The different diameters obtained from a particle size distribution allow the complex information of the particle size distribution to be reduced to a few parameters for a more convenient use. However, one must not forget that mean diameters have no "physical" meaning for multimodal distributions, which are often met in the comminution area. In our study, it was decided to use the following mean diameters for sieving, with $x_{\mathrm{i}}=$ mass fraction of solid collected on sieve of mean size diameter $d_{\mathrm{ai}}$ :

- the arithmetic mean diameter for sieving: $d_{\mathrm{m}}=\Sigma x_{\mathrm{i}} d_{\mathrm{ai}}$; - the harmonic mean diameter $d_{\mathrm{h}}=1 /\left(\sum x_{\mathrm{i}} / d_{\mathrm{ai}}\right)$.

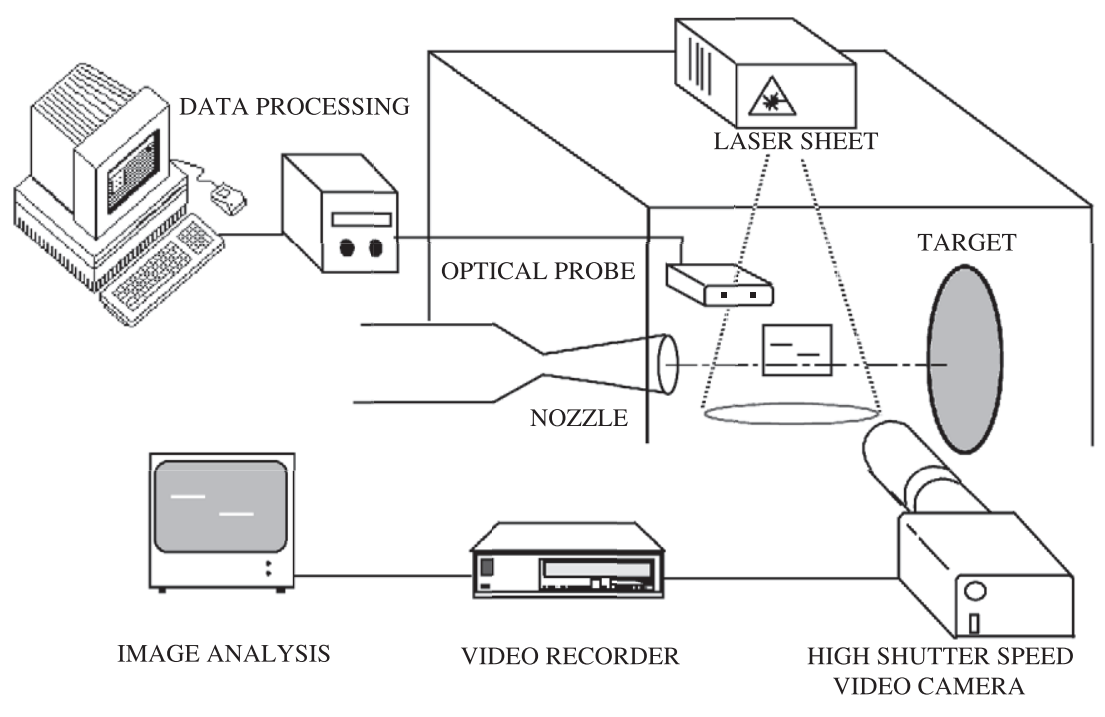

Fig. 2. Experimental velocimetry systems. 
There are many ways of characterising the grindability of powders by fineness criteria. They may be put into three groups:

- those defined on the basis of mean diameters (ratio of initial mean diameter $d_{\mathrm{i}}$ to the final mean diameter $d_{\mathrm{f}}$, ratio of specific surface areas, etc.);

- those defined by the amount of fines created;

- surface-based criteria (amount of surface created as measured by permeability, adsorption, or calculated from particle size distributions).

One knows that these fineness criteria are reducing the particle size distribution information to one single value. They are not showing how individual sieve cuts break, but for this first step of the study, it was decided to use "simple" parameters. The aim is to be able to follow the breakage phenomena of different powders, in order to have general grinding profiles easy to compare.

In this paper we choose to reduce the information of the particle size distributions into three "handy" parameters which, as it will be shown later, are sufficient to compare our studied powders:

- the size reduction ratio, defined from the arithmetic mean diameter: $d_{\mathrm{i}} / d_{\mathrm{f}}$. It gives information mainly on the largest fragments.

- the weight percentage of particles finer than $40 \mu \mathrm{m}$ : $\%$ fines $<40 \mu \mathrm{m}$. It is a very attrition-sensible criterion and gives mainly information on the beginning of fragmentation, corresponding to the weakest particles.

- the specific surface area derived from the harmonic mean diameter: $a_{\mathrm{s}}=6 \rho_{\mathrm{s}}^{-1} d_{\mathrm{h}}^{-1}$. It gives information mainly on the smallest fragments.

\section{Tested solids}

The powders impacted in the experimental rig cover a wide range of different materials from minerals to polymers. Table 1 shows the physical properties of the studied samples, when provided by the suppliers. The varied morphologies of the grains are shown in Fig. 3a and $\mathrm{b}$.

Table 1

Physical properties of the studied solids

\begin{tabular}{lclllll}
\hline Material & $\begin{array}{l}\text { Diameter, Density } \\
d_{\mathrm{m}}(\mu \mathrm{m})\end{array}$ & $\begin{array}{l}\text { Specific } \\
\left(\mathrm{kg} \mathrm{m}^{-3}\right) \\
\mathrm{area}^{2} a_{\mathrm{s}} \\
\left(\mathrm{m}^{2} \mathrm{~kg}^{-1}\right)\end{array}$ & $\begin{array}{l}\text { Young's } \\
\text { modulus } \\
(\mathrm{GPa})\end{array}$ & $\begin{array}{l}\text { Poisson } \\
\text { ratio }(-)\end{array}$ & $\begin{array}{l}\text { Mohs } \\
\text { hardness }\end{array}$ \\
\hline Glass & 129 & 2460 & 19 & 70 & 0.25 & 6 \\
Sand & 109 & 2640 & 21 & 74 & 0.16 & 6 \\
Polyamide & 123 & 1030 & 50 & 0.012 & - & 3 \\
$\mathrm{NaCl}$ & 400 & 2160 & 7 & 43.9 & - & 2.5 \\
$\mathrm{Al}(\mathrm{OH})_{3}$ & 93 & 2350 & 27 & - & - & 3.5 \\
PMMA & 173 & 1180 & 33 & 3.3 & 0.4 & 3 \\
\hline
\end{tabular}

- The glass beads are spherical with smooth surface, soda lime microspheres. They are a $90-$ to $150-\mu \mathrm{m}$ sieve cut.

- The sand particles are a 90 - to $125-\mu \mathrm{m}$ sieve cut. It has a composition which is more than $99 \% \mathrm{SiO}_{2}$ with traces of other metal oxides.

- Hydrargillite $\mathrm{Al}(\mathrm{OH})_{3}$ is obtained by the so-called Bayer process. The structure of the particle is an accretion of grains which are themselves assemblies of platelets [4]. The particle size distribution ranges from 40 to $140 \mu \mathrm{m}$.

- The polyamide 11 is a 40 - to $160-\mu$ m polymer with semicrystalline structure. It is actually pre-ground and predried.

- The salt $\mathrm{NaCl}$ has cubic crystals. It is produced by evaporation of pickling brine saturated in natural rock salt. The particles are a $315-$ to $500-\mu \mathrm{m}$ sieve cut.

- The PMMA amorphous polymer is obtained from conventional suspension polymerisation, providing for very spherical particles. The particle size distribution ranges from 100 to $250 \mu \mathrm{m}$.

\section{Results}

\subsection{Preliminary study}

As the aim is to study the fragmentation of particles on the target, it is essential that the incident particles are not deviated by the layer of air moving laterally at the target. The inertia of the particles must therefore be sufficient for their trajectory not to be disturbed by the lines of flow near the stagnation zone. Previous work [5] gave an dimensionless inertia number $\lambda$, appearing from the constitutive equations for two-phase flows. It is defined as the ratio of the aerodynamic time response and the flow characteristic time (see expression in nomenclature). It was shown that if the inertia number $\lambda$ is larger than 1 , the particle trajectories are not disturbed by the flow lines. It was checked that all the tested solids would fulfil that condition (see Fig. 4). Even for the smallest sieve cut from the feed powder of hydrargillite $(32-45 \mu \mathrm{m})$, the inertia number is larger than 10 .

Furthermore, before using a silicon carbide target for the experimental programme, tests were performed with a rubber target which does not give impact fragmentation. The aim was to determine the importance of attrition in the accelerating nozzle or in the cyclone collectors under given operating conditions. It was found that with very dilute jets $\left(\mu=W_{\mathrm{j}} / W_{\mathrm{s}} \approx 10^{-2}\right)$, there was no significant difference in mean diameter or in the shape of the particle size distributions before and after impact. Thus, under these conditions, there is no extraneous attrition phenomena and fragments are only produced at impact on the SiC target.

\subsection{Particle size distributions}

The results of impact experiments with glass beads are shown in Fig. 5 as density distributions. First of all, it can be 

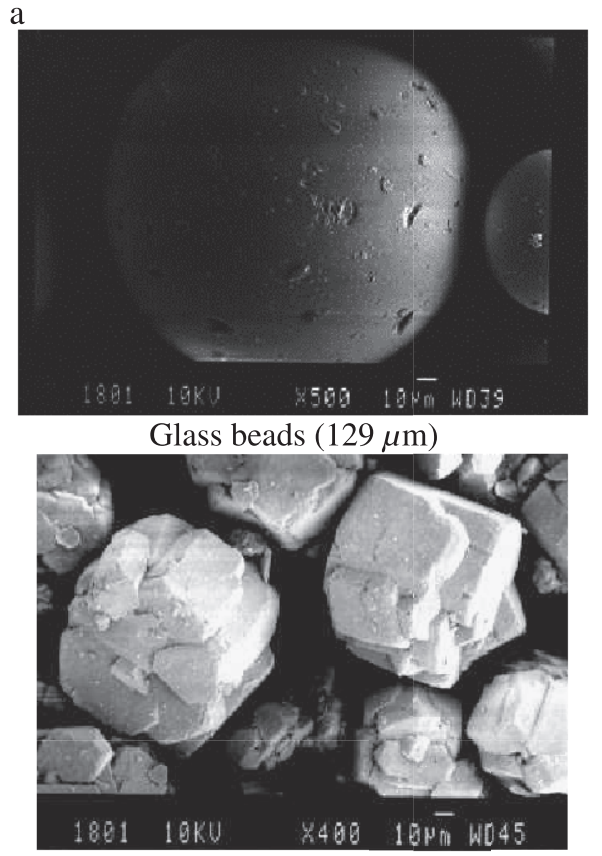

European $\mathrm{A} 1(\mathrm{OH}) 3(93 \mu \mathrm{m})$

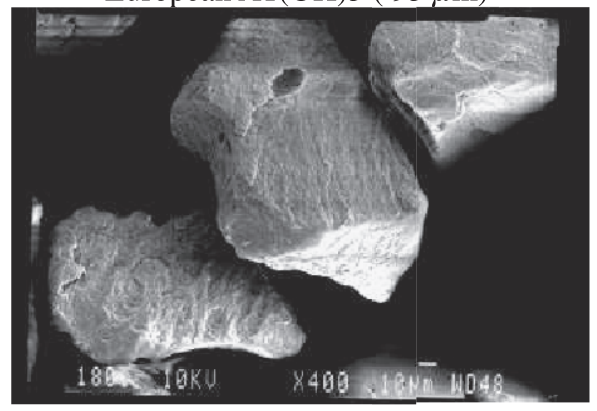

Polyamide $11(123 \mu \mathrm{m})$

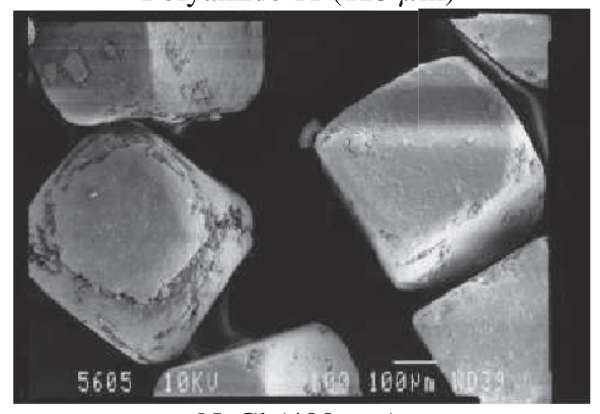

$\mathrm{NaCl}(400 \mu \mathrm{m})$

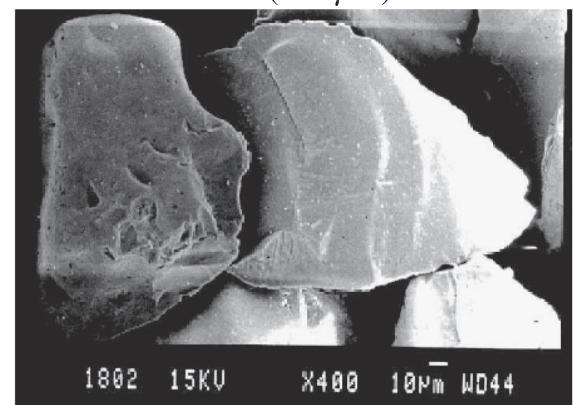

Sand(108 $\mu \mathrm{m})$

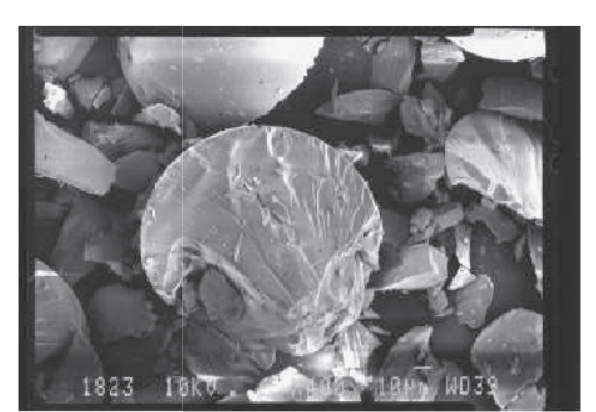

Broken at $125 \mathrm{~m} / \mathrm{s}$

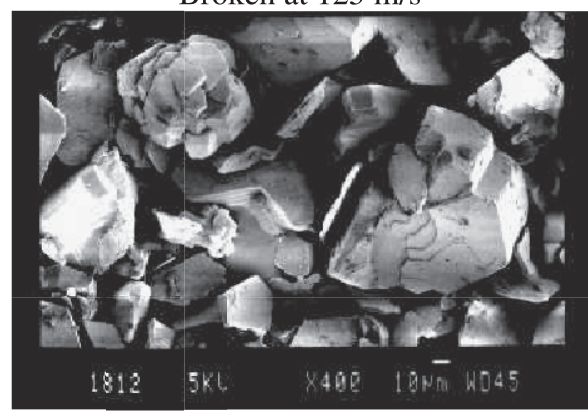

Broken at $155 \mathrm{~m} / \mathrm{s}$

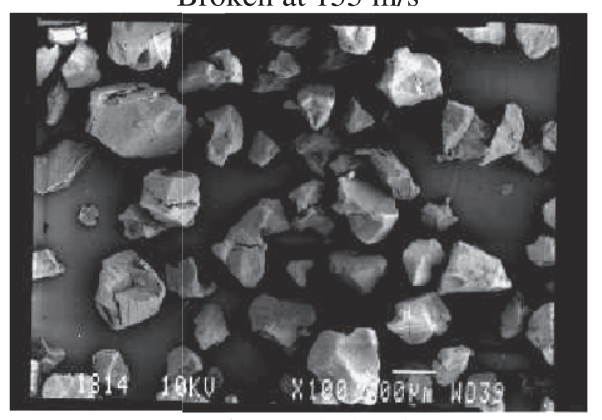

Broken at $270 \mathrm{~m} / \mathrm{s}$

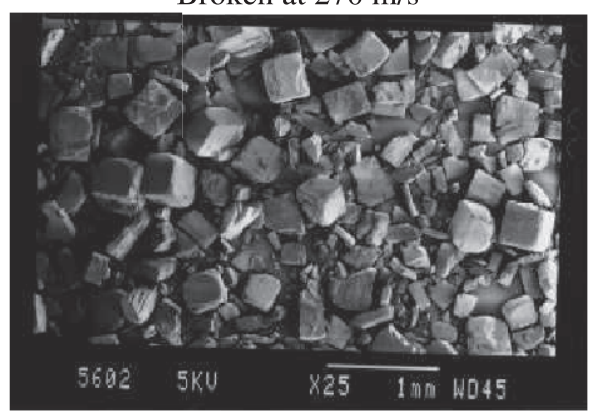

Broken at $47 \mathrm{~m} / \mathrm{s}$

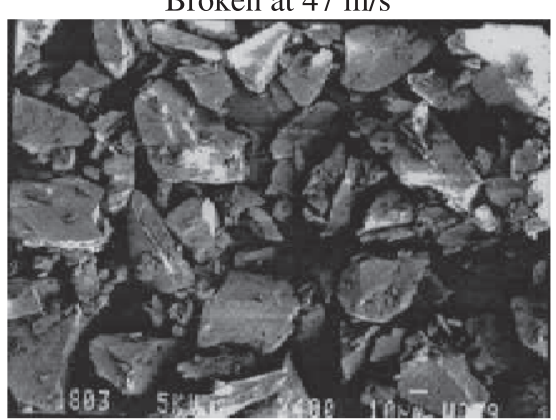

Broken at $170 \mathrm{~m} / \mathrm{s}$

Fig. 3. (a) and (b) SEM pictures of the studied solids. 

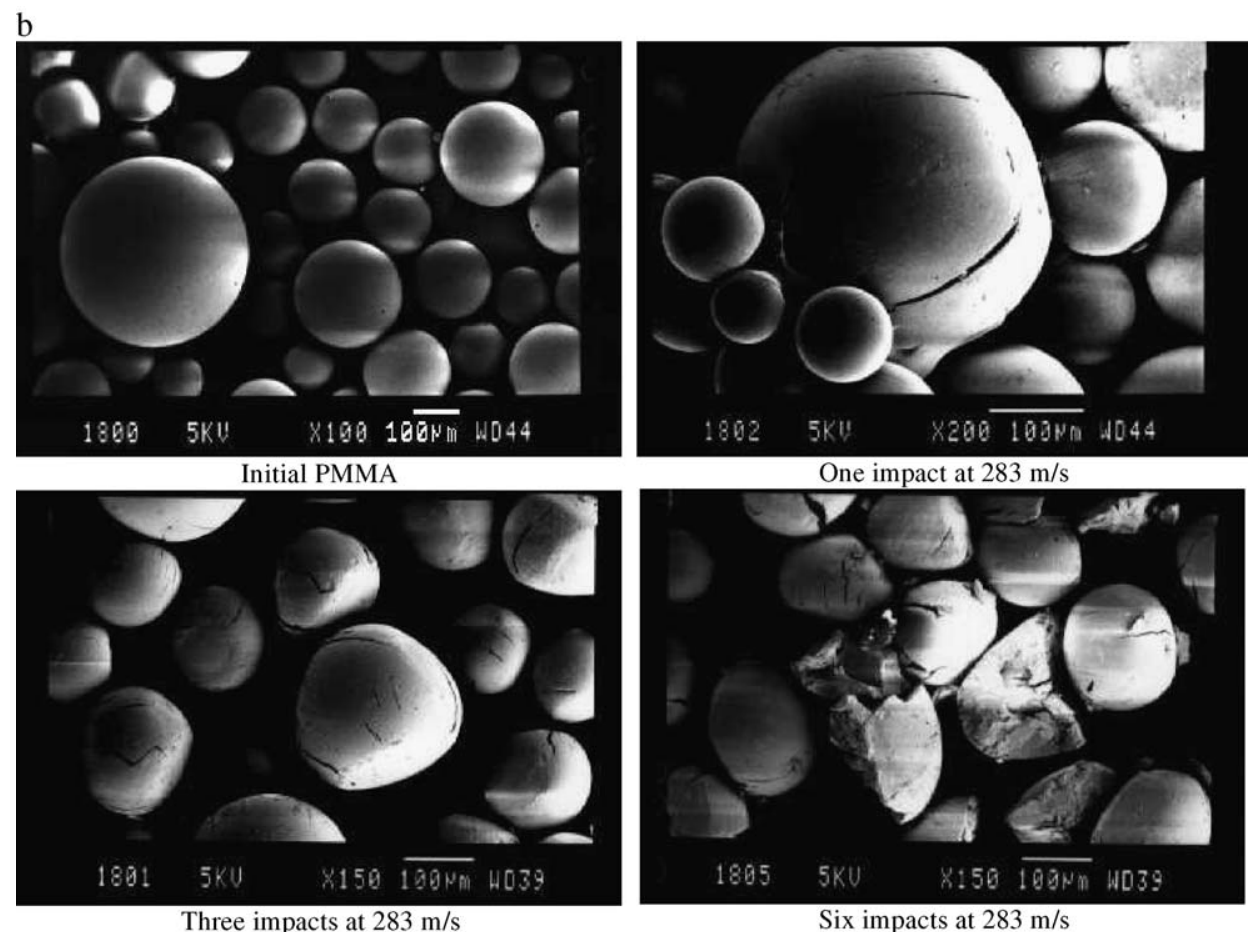

Fig. 3 (continued).

seen that these distributions are essentially monomodal, which allows the use of mean diameters to characterise the results and consequently to define fineness criteria on the basis of mean diameters. This conclusion is also true for the other powders studied in this paper. Secondly, the change in the location of the peaks between the initial material and the fragmented material gives information about the evolution of the different particle size classes. Even if the whole information of the particle size distribution is not used here, the diameters and derived fineness criteria will allow us to study the impact behaviour of our solids.

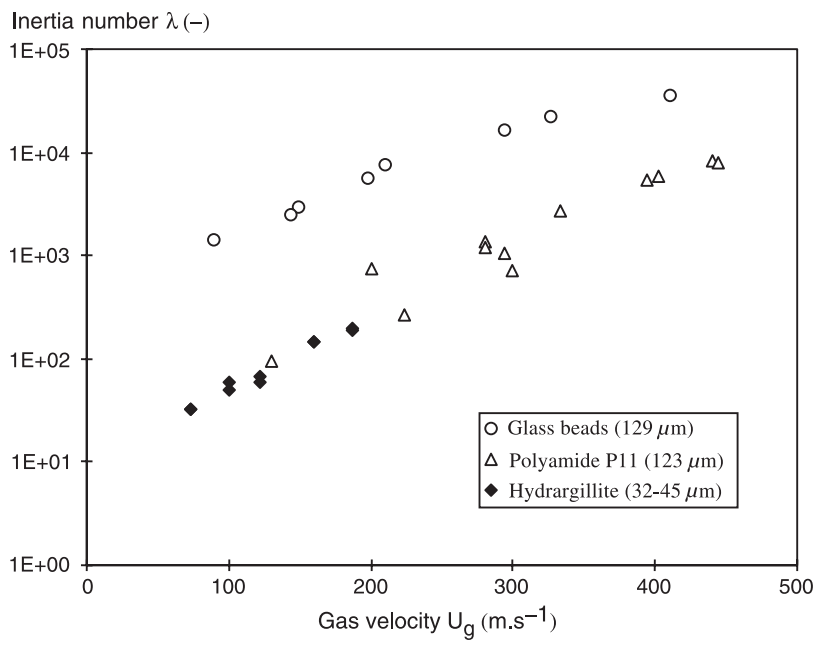

Fig. 4. Variation of inertia number with gas velocity.

\subsection{Size reduction ratio}

Fig. 6a shows the change of the size reduction ratio $d_{\mathrm{i}} / d_{\mathrm{f}}$ with the impact velocity $V_{\mathrm{s}}$, for different solids. Fig. $6 \mathrm{~b}$ shows the change of the size reduction ratio $d_{\mathrm{i}} / d_{\mathrm{f}}$ with the impact kinetic energy $E_{\mathrm{s}}=0.5 \rho_{\mathrm{s}} V_{\mathrm{s}}^{2}$, for different solids, with a scale that is chosen to highlight the zone of small energy impacts. In Fig. 6a, when the solid can be broken, there are two zones separated by a transition velocity $V_{\text {so }}$ called the velocity attrition threshold. In Fig. 6b, the same pattern can

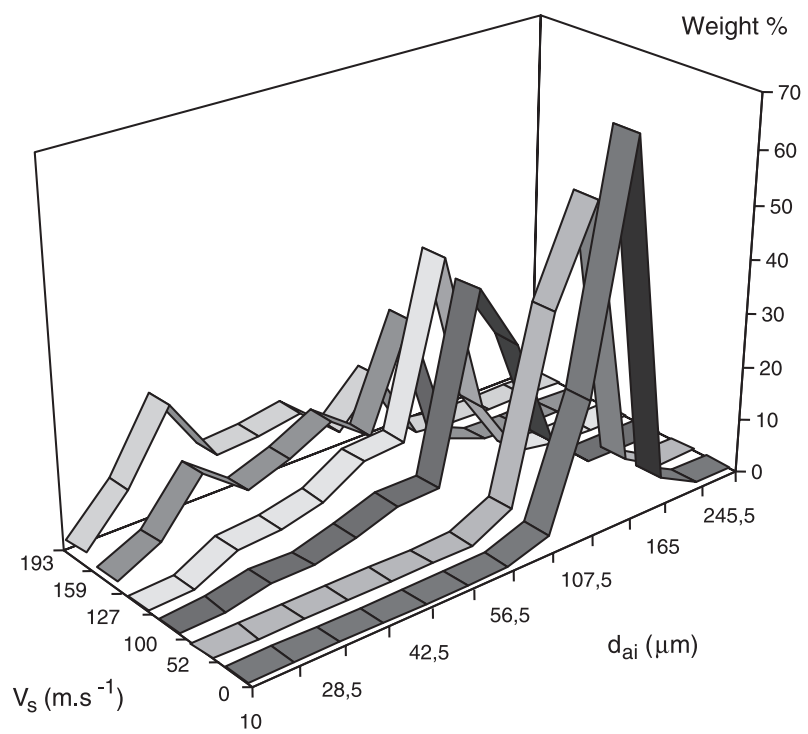

Fig. 5. Particle size distributions for glass beads. 


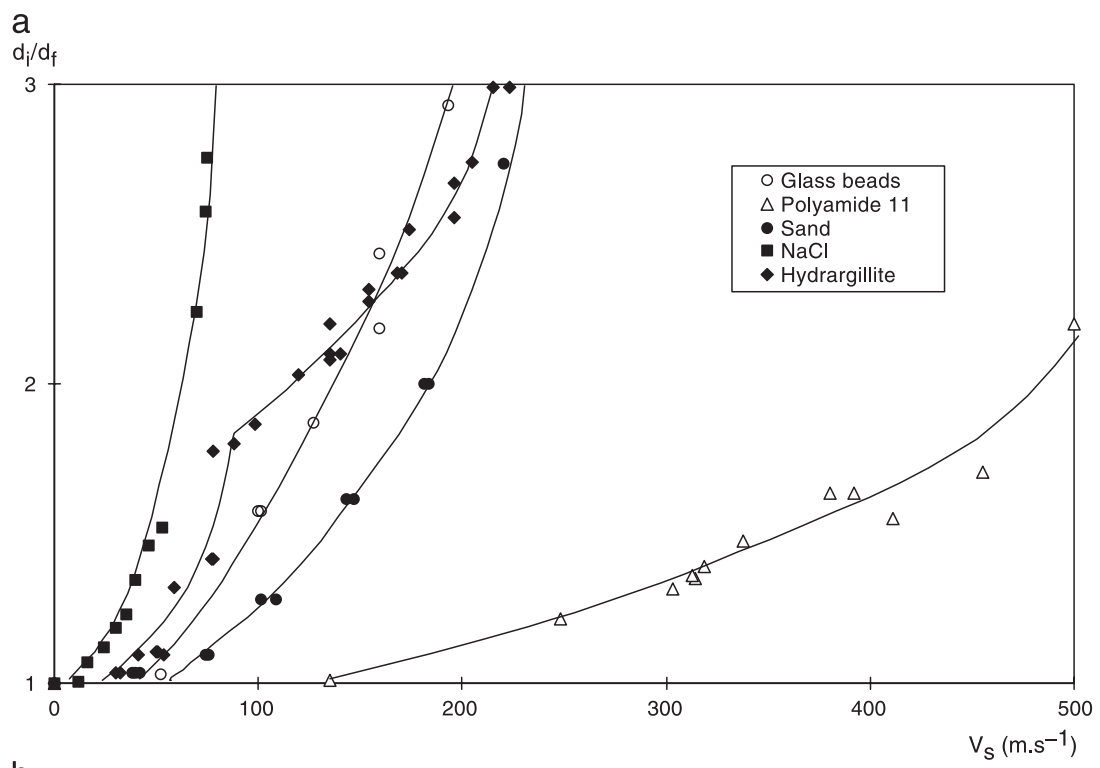

$\mathrm{b}$

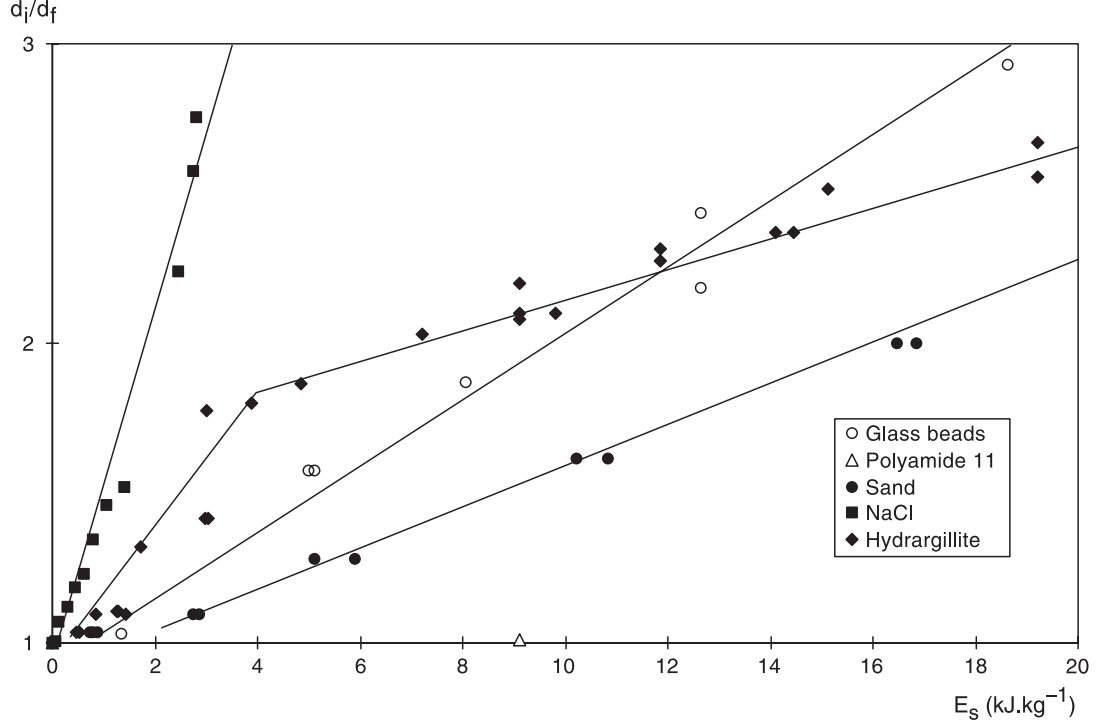

Fig. 6. (a) Size reduction ratio evolution with impact velocity. (b) Size reduction ratio evolution with impact kinetic energy.

be seen with the corresponding kinetic energy attrition threshold $E_{\mathrm{so}}=0.5 \rho_{\mathrm{s}} V_{\mathrm{so}}^{2}$. The transition $V_{\text {so }}$ (respectively $E_{\mathrm{so}}$ ) is obtained in Fig. 6a (respectively Fig. 6b) by extrapolation of the curves to $d_{\mathrm{i}} / d_{\mathrm{f}}$ equal to 1 . Table 2 gives the characteristic values determined for the different tested solids. The same patterns are observed for the three fineness criteria: $d_{\mathrm{i}} / d_{\mathrm{f}}, a_{\mathrm{s}}$ and the \%fines $<40 \mu \mathrm{m}$ plotted vs. $V_{\mathrm{s}}$ or $E_{\mathrm{s}}$. It seems that the thresholds depend only on the nature of the material, its particle size and on the nature and surface state of the target, regardless of the fragmentation criterion that is used [4]. The threshold corresponds to the beginning of the breakage of the weakest particles of the powder, but as there is a distribution of strength among the particles of the powder [6], all the first broken particles do not probably have exactly the same size. The interest of determining such a parameter is then that one knows if a powder will produce broken fragments in his process (handling, transport, etc.). If the powder is experiencing impacts at velocities higher than the attrition velocity threshold, broken fragments will appear.

Table 2

Threshold parameters for the studied solids

\begin{tabular}{lcllll}
\hline Material & $\begin{array}{l}V_{\mathrm{so}} \\
\left(\mathrm{m} \mathrm{s}^{-1}\right)\end{array}$ & $\begin{array}{l}E_{\mathrm{so}}\left(\mathrm{MJ} \mathrm{m}^{-3}\right) \\
\left(\mathrm{kJ} \mathrm{kg}^{-1}\right)\end{array}$ & $\begin{array}{l}V_{\mathrm{sc}} \\
\left(\mathrm{m} \mathrm{s}^{-1}\right)\end{array}$ & $\begin{array}{l}E_{\mathrm{sc}}\left(\mathrm{MJ} \mathrm{m}^{-3}\right) \\
\left(\mathrm{kJ} \mathrm{kg}^{-1}\right)\end{array}$ & $\begin{array}{l}p \\
\left(\mathrm{~m}^{2} \mathrm{~kJ}^{-1}\right)\end{array}$ \\
\hline Glass & 46 & 2.6 & - & - & 2.7 \\
& & 1.1 & & & \\
Sand & 65 & 5.6 & - & - & 2.7 \\
& & 2.1 & & & \\
Polyamide & 125 & 8.1 & - & - & 0.5 \\
& & 7.9 & & & \\
$\mathrm{NaCl}$ & 11 & 0.1 & - & - & 5.5 \\
& & 0.06 & & & \\
$\mathrm{Al}(\mathrm{OH})_{3}$ & 31 & 1.1 & 88 & 9.1 & 9.0 \\
& & 0.5 & & 3.9 & 2.2 \\
\hline
\end{tabular}




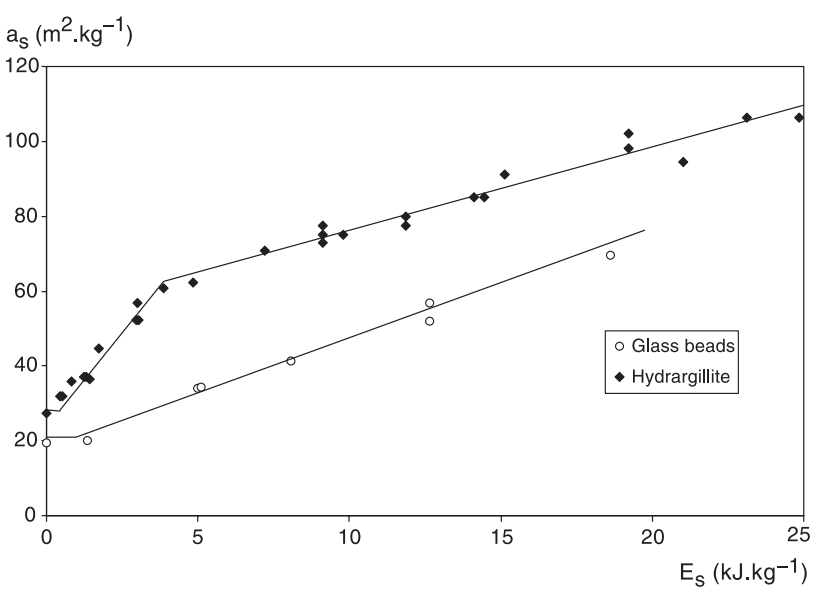

Fig. 7. Specific surface evolution for glass beads and $\mathrm{Al}(\mathrm{OH})_{3}$.

The following discussion will use the generic fineness criterion $\xi$ corresponding to one of the three parameters: $d_{\mathrm{i}} /$ $d_{\mathrm{f}}, a_{\mathrm{s}}$ or the $\%$ fines $<40 \mu \mathrm{m}$. The same conclusions apply whatever the chosen fineness criterion. Below the attrition threshold, the impact is probably elastic, according to the SEM observation, even if internal damage is possible. Above that limit, the provided kinetic energy ( $\left.\propto V_{\mathrm{s}}^{2}\right)$ always leads to fragmentation. Three types of behaviour are found. Two are illustrated in Fig. 7 with the variation of the specific surface area $a_{\mathrm{s}}$ vs. the kinetic energy $E_{\mathrm{s}}$ for two solids that exhibit these two typical fragmentation profiles: glass and hydrargillite.

- For glass, but also for sand, polyamide and $\mathrm{NaCl}$, above the attrition threshold, a linear increase of any fineness criterion with the kinetic energy (i.e. the square of the impact velocity) can be proposed. Fig. 7 shows what happens for glass beads between $a_{\mathrm{s}}$ and $E_{\mathrm{s}}$. This is in accordance with the literature. For a brittle material (e.g. glass), Griffith theory [7] explains the observations. The basic hypothesis is the creation of cracks from flaws that generally exist in any solid. Their propagation is immediate and fracture occurs. The more energy provided, the denser the crack pattern [8]. SEM pictures reveal a crack pattern that originates from a short distance below the impact point, propagating in the opposite direction (also seen in Refs. [8,9]). This can be seen at any velocity, which would suggest that only one fracture mechanism is operating for such materials. Polyamide belongs to this group of brittle materials because of its semi-crystalline structure that is prone to fragile rupture.

- On the other hand, for hydrargillite, past the attrition threshold, there are two breakage regimes (linear) separated by a critical energy $E_{\mathrm{sc}}$ (Fig. 7). Hydrargillite's behaviour is explained by its complex structure [4]. A grain is actually an association of platelets which are themselves piles of sheets. Thus between the attrition and critical threshold, the low energy level supplied to the particles is only able to provoke the breaking of the edges of the crystal or of the platelets. The first mechanism corresponds to the rupture by chipping and splitting of the grain joints of the platelets structure. The weakest bonds are broken first giving smaller aggregates. Past the critical threshold, the fragments look completely different on the SEM pictures. There is a cleavage of the platelets and their destruction yields sheets and fragments of platelets. The new mechanism of cleavage-breakage tends to break a stronger structure, hence the reduction in slope in the graphs.

- Finally, for the amorphous polymer PMMA, no fragmentation occurs in one impact. SEM pictures show only flattened particles and a crack pattern that does not lead to fracture (see Fig. 3b). The 173- $\mu \mathrm{m}$ PMMA spheres exhibit a ductile behaviour during the tests.

\subsection{Percentage of fines-specific area}

Whatever the solid, the changes of the weight percentage finer than $40 \mu \mathrm{m}$ and the specific surface area as velocity increases are similar to those seen above. Fig. 8 shows the change of the three different parameters for the impact of hydrargillite. As can be seen, the thresholds are located in the same place. These parameters are equivalent as the information obtained from them is the same.

\subsection{Grindability parameters}

\subsubsection{The attrition threshold}

The attrition threshold $E_{\mathrm{so}}$ represents the minimum energy to provide to a powder to cause failure. It depends, a priori, on the powder and the experimental rig. However, it has been shown [2] that if the target has a large enough Young's modulus, the transition data are only dependent on the powder: nature (chemical composition, structure) and its particle size distribution.

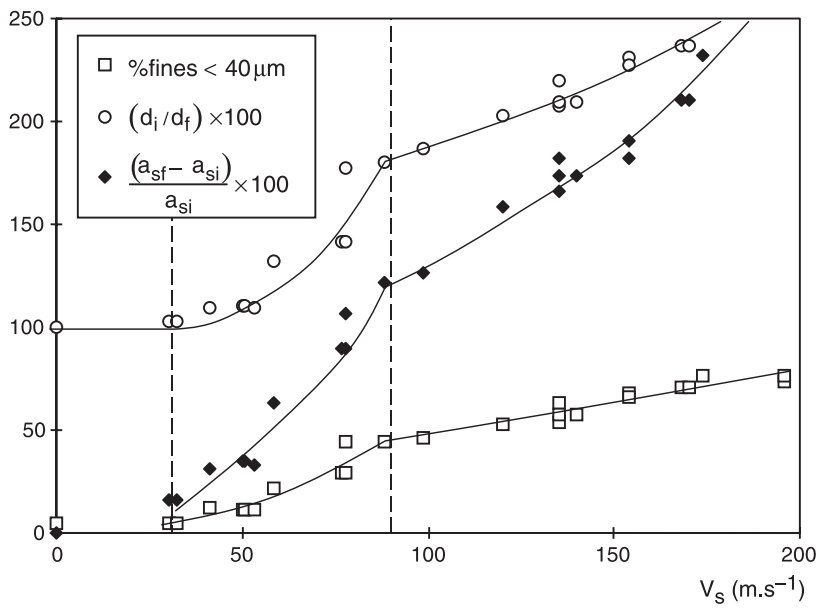

Fig. 8. Variation of different fineness criteria for $\mathrm{Al}(\mathrm{OH})_{3}$. 
$V_{\text {so }}$ is a useful comparison parameter, as it answers to the questions: which solid will break first? or which solid is the "weakest" for attrition by impact?

There appears to be no relation between the threshold velocity and Mohs hardness. A solid can be "hard" and brittle (e.g. glass). Besides, glass and sand have the same hardness but the latter can withstand, without breaking, impacts velocities up to 1.5 times those for glass.

\subsubsection{The grindability index $p$}

If the curve $a_{\mathrm{s}}$ vs. $E_{\mathrm{s}}$ is a straight line above the attrition $E_{\text {so }}$, its slope, $p$, has the units of $\mathrm{m}^{2} \mathrm{~kJ}^{-1}$. It can be interpreted as the amount of created surface per kilojoule, or more precisely as the increase of surface for an increase of provided energy. Thus, it represents an ability of breakage: the larger $p$, the more surface will be created for a given energy.

However, one must keep in mind that $V_{\text {so }}$ and $p$ contain different information. A solid with small $V_{\text {so }}$ can break and create more surface per kilojoule (i.e. with large $p$ ) than one with a larger attrition threshold. It can also be observed that even if glass and sand have the same grindability $p=2.7 \mathrm{~m}^{2} /$ $\mathrm{kJ}$, the former is more sensitive to attrition: $V_{\text {so }}$ (sand) $=65$ $\mathrm{m} / \mathrm{s}$ and $V_{\text {so }}$ (glass) $=46 \mathrm{~m} / \mathrm{s}$.

\subsection{Comparison with the literature}

Many authors have studied the relationship between the fracture energy and the mechanical characteristics of the solids $[10,11]$. They rely on the Hertzian theory [12]. Eq. (1) enables an evaluation of the attrition threshold for different materials [10].

$V_{\text {so }}=\left(\frac{4.99}{\pi \rho_{\mathrm{s}}}\right)^{1 / 2}\left(\frac{1-v^{2}}{Y}\right)^{2 / 6}\left(\frac{\pi \sigma_{\mathrm{c}}(28+20 v)}{84}\right)^{5 / 6}$

Tables 3 and 4 compare the attrition threshold " $V_{\text {so- }}$ experiment" obtained for the three tested solids with " $V_{\mathrm{so}^{-}}$ calculated" obtained from three similar solids from Eq. (1), with physical and mechanical data found in the literature [13-15].

Even if the data come from different sources, the results correlate well with Eq. (1). This is not surprising as, even if these powders are not "ideal particles", they nevertheless have a marked brittle behaviour.

The ductile behaviour observed with our PMMA spheres would be an example of the existence of a brittle-ductile transition. Okuda and Choi [16] succeeded in fragmenting 9.8-mm particles of PMMA, whereas it was not possible for our $0.173-\mathrm{mm}$ spheres to break. This result is in agreement

Table 3

Experimental data used for comparison with Eq. (1) application

\begin{tabular}{lc}
\hline Studied solid & $V_{\text {so-experiment }\left(\mathrm{m} \mathrm{s}^{-1}\right)}$ \\
\hline Glass beads $129 \mu \mathrm{m}$ & 46 \\
PA11 $123 \mu \mathrm{m}$ & 125 \\
NaCl $315-400 \mu \mathrm{m}$ & 11 \\
\hline
\end{tabular}

Table 4

Examples of Eq. (1) application

\begin{tabular}{|c|c|c|c|c|}
\hline $\begin{array}{l}\text { Reference } \\
\text { literature }\end{array}$ & $\begin{array}{l}\text { Density } \\
\left(\mathrm{kg} \mathrm{m}^{-3}\right)\end{array}$ & $\begin{array}{l}\text { Poisson } \\
\text { ratio }(-)\end{array}$ & $\sigma_{\mathrm{c}}(\mathrm{Pa})$ & $\begin{array}{l}V_{\text {so }} \text {-calculated } \\
\left(\mathrm{m} \mathrm{s}^{-1}\right)\end{array}$ \\
\hline $\begin{array}{l}\text { Glass beads } \\
\qquad 775 \mu \mathrm{m}[11]\end{array}$ & 2500 & $0.25^{\mathrm{a}}$ & $\begin{array}{l}70 \times 10^{9} \\
\text { (tensile particle } \\
\text { strength) }\end{array}$ & 31 \\
\hline Nylon 11 [12] & $1030^{\mathrm{a}}$ & $0.3^{\mathrm{a}}$ & $\begin{array}{l}44 \times 10^{6} \\
\text { (tensile resistance) }\end{array}$ & 103 \\
\hline $\begin{array}{l}\text { Salt } 425-500 \\
\qquad \mu \mathrm{m}[13]\end{array}$ & $2160^{\mathrm{a}}$ & $0.3^{\mathrm{a}}$ & $\begin{array}{l}12 \times 10^{6} \\
\text { (single particle } \\
\text { failure stress) }\end{array}$ & 8 \\
\hline
\end{tabular}

${ }^{\mathrm{a}}$ Estimated data.

with the brittle-ductile transition theory that predicts for PMMA a critical diameter of $0.303 \mathrm{~mm}$ below which failure by chipping in the semi-brittle mode is not possible. Hagan [17] showed that the ultimate particle size below which the particle can only be deformed elastically can be approximated by:

$l_{\mathrm{u}} \approx 30\left(K_{\mathrm{c}} / H\right)^{2}$

This relation is based on crack nucleation and propagation. Actually, for a given threshold load, a crack of a given size nucleates. The hypothesis of this approach is that the largest flaw size determines the critical specimen size for the ductile-brittle transition in comminution.

In comparison, the critical specimen size for glass predicted by the above analysis is about $0.5 \mu \mathrm{m}$, which is in excellent agreement with the literature $[17,18]$. Other results are obtained with different $\mathrm{NaCl}: l_{\mathrm{u}} \approx 27-83 \mu \mathrm{m}$ $[19,20]$.

Nevertheless, one must be cautious with the limiting size notion, as often a grinding limit size is observed not because of the material but because of the experimental apparatus limitations.

\section{Classification of the types of behaviour at impact}

So far three types of behaviour at impact on a target have been found.

\subsection{Brittle}

The fineness criterion $\xi$ follows a linear increase with the kinetic energy above the attrition threshold. Two parameters can be determined from the curves: the attrition threshold and the slope of the straight line. Hence, two comparisons can be made between materials showing brittle failure.

The threshold value, $V_{\text {so }}$ or $E_{\mathrm{so}}$, gives information on the resistance to attrition by impact. Sometimes, when the material is highly sensitive to attrition, it is not possible to determine the attrition threshold by extrapolation. In such a case, one must be sure that the fragmentation is only happening on the target and not on the walls of the rig, for instance. 
The slope $p$ quantifies an ease of breakage. The greater $p$, the easier a material is broken for the same energy increment. If $\xi$ is the specific area, the slope represents the amount of created surface per kilojoule.

The attrition threshold and the grindability index $p$ are complementary criteria for characterising the behaviour at impact of a solid.

\subsection{Complex}

There are two different brittle behaviours before and after a critical velocity or energy (hydrargillite, for example). Below that threshold, the evolution is similar to brittle materials. Above the critical change, the fracture efficiency can be smaller or larger, as if a "weaker" or "stronger" material is being broken.

\subsection{Elastic-plastic}

There is no fracture in one impact. Measuring the importance of the plastic deformation is a way of classifying such materials. Investigation of higher energy impact is necessary to confirm the brittle-ductile transition.

\subsection{Others}

The literature gives examples of materials that do not have a linear behaviour. In that situation, it is impossible to determine a constant grindability, but it is still possible to compare the tangent of the curve at a given energy.

The question of the existence of stagnation at a level of energy is linked to the existence of a limiting size [17,18,21-23].

\section{Results with polyamide}

Several tests were performed with polyamide at very high kinetic energies, using helium as the carrier gas instead of air. SEM pictures reveal some melted part in some particles, but several particles are not melted at all. For the particles that melted during the impact, the temperature could have risen up locally to at least $180{ }^{\circ} \mathrm{C}$, the melting point for our polyamide 11 . Another explanation lies in the combination of plastic deformation and inertia. If the temperature is larger than the glass transition temperature $T_{\mathrm{v}}=38{ }^{\circ} \mathrm{C}$, the particle could deform in such a way up to the fibrous aspect observed.

\section{Multi-impact results}

\subsection{Hydrargillites}

Hydrargillite particles of initial size of $93 \mu \mathrm{m}$ were subjected to repeated impacts at the same velocity. The whole fraction of particles (broken and unbroken) was reimpacted. Fig. 9 shows the change of the mean diameter of the impacted sample as a function of the number of impacts for different impact velocities. These results may be interpreted on the basis of $E_{\mathrm{so}}$ and $E_{\mathrm{sc}}$ used in the single impact study.

- At a velocity of $24 \mathrm{~m} / \mathrm{s}$, the attrition threshold is not reached and there is no change in the particle size of the powder: for the 93- $\mu \mathrm{m}$ size particles of hydrargillite, the energy supplied is smaller than $E_{\text {so }}$.

- For higher velocities, there is no more change after three impacts. If $E_{\mathrm{so}}<E_{\mathrm{s}}<E_{\mathrm{sc}}$ (i.e. a velocity lower than $88 \mathrm{~m} /$ s), there seems to be an asymptote at $40 \mu \mathrm{m}$, which would correspond to the smallest monocrystals of hydrargillite. In this domain of energy, a multiplication of the number of impacts will never give particles smaller than $\approx 40$ $\mu \mathrm{m}$. To obtain smaller size particles, it is necessary to get over the potential barrier $E_{\mathrm{sc}}$.

- If $E_{\mathrm{s}}>E_{\mathrm{sc}}$, there also seems to be an asymptote after three or four impacts. Cleavage-grinding first gives smaller tablets which then may be ground to give tablet fragments smaller than $40 \mu \mathrm{m}$.

This kind of result has often been reported in the literature: three impacts for $\mathrm{NaCO}_{3}$ [24]; seven impacts for polystyrene [13]; five for $\mathrm{CaCO}_{3}$ [25]. The reason for this asymptote is not well known, but it seems that the efficiency of grinding enters in the problem. An impact is never 100\% efficient, because, for example, of the particle orientation at impact. Different orientation will not give the same stress field in all the particles. The first impacts will only break several bonds. All the bonds corresponding to one energy level, statistically, will only be broken after several impacts. There is no change afterward and stagnation is observed when all possibilities for rupture at a given velocity have been used.

One consequence of these results is that, with the followed methodology, supplying all the kinetic energy to

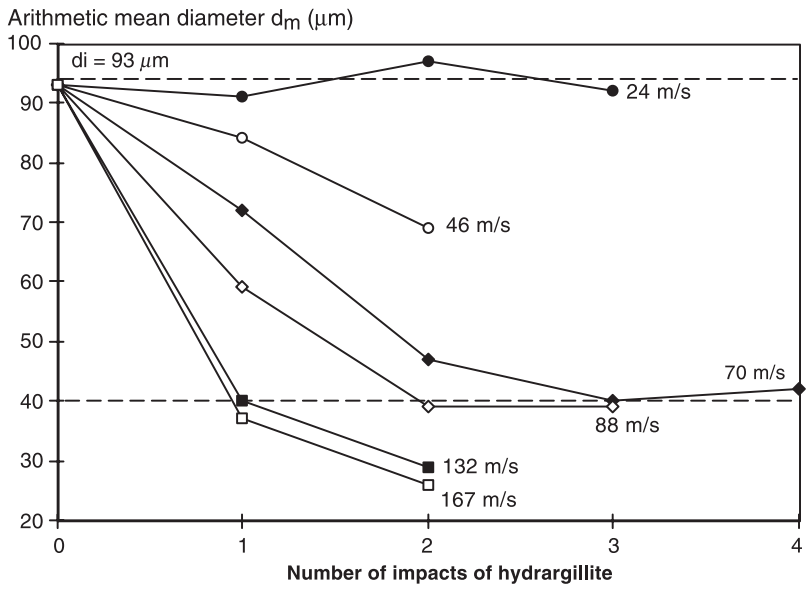

Fig. 9. Multi-impact results for $\mathrm{Al}(\mathrm{OH})_{3}$. 


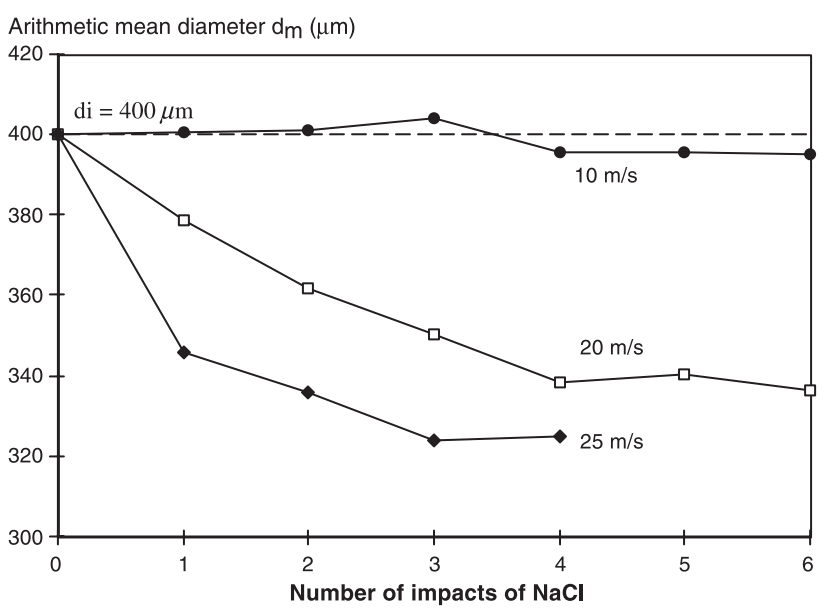

Fig. 10. Multi-impact results for $\mathrm{NaCl}$.

rupture a solid in one impact is not the same as supplying it in several impacts.

\section{2. $\mathrm{NaCl}$}

A size range of $315-500 \mu \mathrm{m}$ of salt particles was impacted several times for different velocities: one smaller than the attrition threshold and two over it. However, contrary to the test with hydrargillite, the same cut size $(315-500 \mu \mathrm{m})$ was re-impacted. Fig. 10 shows the change of the mean diameter of the impacted sample as a function of the number of impacts for different impact velocities.

Even if the methodology differs from the one used in the hydrargillite's campaign, the results are similar. Below the attrition threshold, no matter what the number of impacts is, no breakage occurs. So, as far as we can say, i.e. six impacts, there is no apparent fatigue phenomenon that leads to fragmentation.

Above the attrition threshold, there is size reduction only until the fourth impact. Further impact did not break the particles significantly: an asymptotical behaviour was

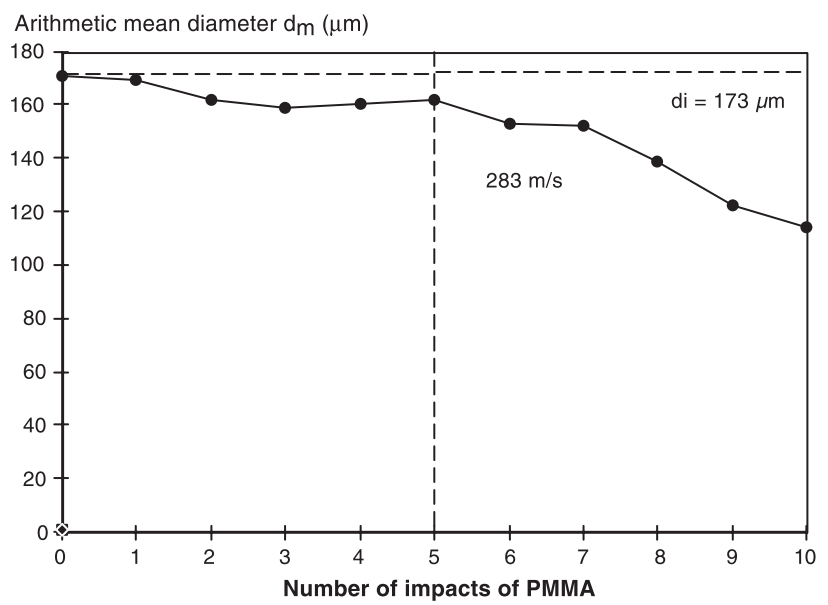

Fig. 11. Multi-impact results for PMMA.

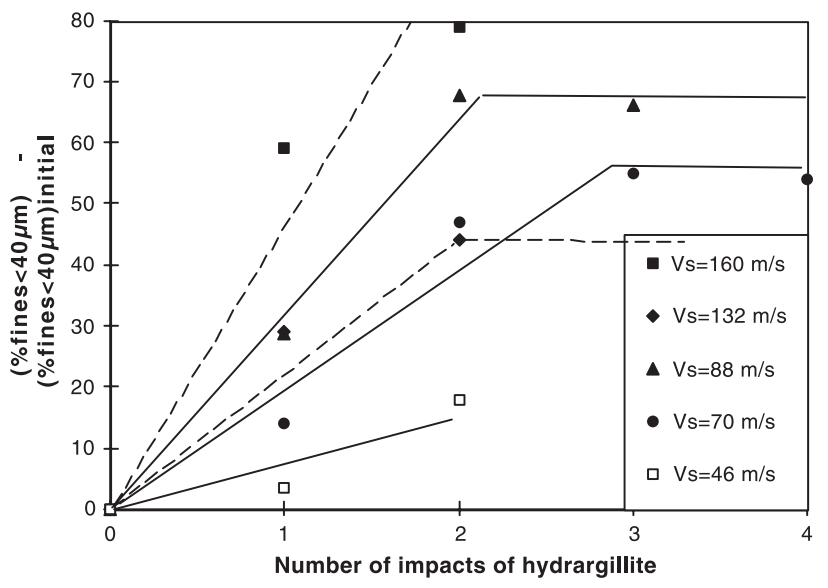

Fig. 12. Multi-impact profiles for $\mathrm{Al}(\mathrm{OH})_{3}$.

found, showing that some fraction of the particles was too strong to break at the velocity used, that is, had a high threshold.

\section{3. $P M M A$}

Repeated impacts were performed with PMMA, which a single impact did not manage to break. The whole fraction is always re-impacted. The aim of these experiments was to see if it was possible to fragment $173-\mu \mathrm{m}$ beads of this material and, if so, after how many impacts. Fig. 11 shows the change of the mean diameter with the number of impacts. Rupture only occurs after five impacts. SEM pictures show that one impact leads to the flattening of the particle at the point of impact, accompanied by large cracks which spread out from the zone of plastic deformation. Several subsequent impacts do not make these cracks propagate further up to failure but further flattenings can be seen to give an increasing degree of fissuring. Even if the solid can store a large amount of impact energy by plastic deformation at the point of shock, a phenomenon of fatigue by creation, densification and propagation of cracks would be an explanation for the breaking.

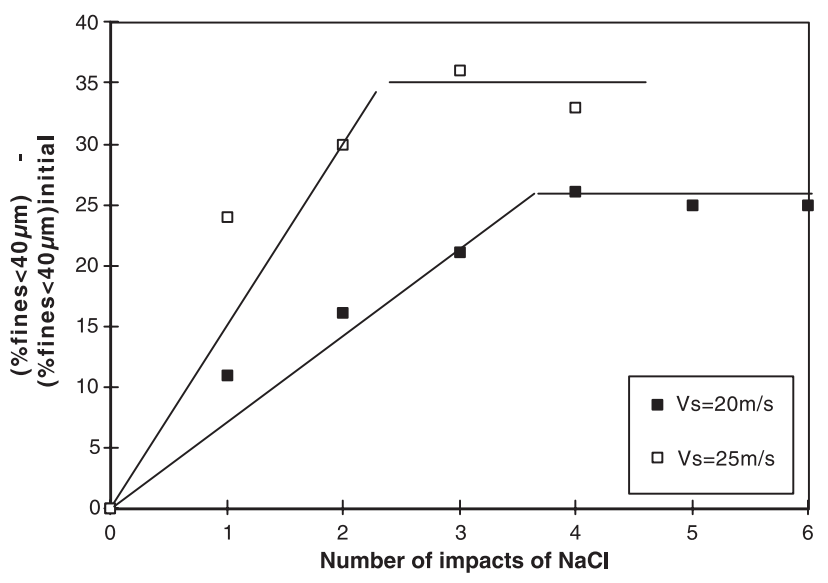

Fig. 13. Multi-impact profiles for $\mathrm{NaCl}$ at 20 and $25 \mathrm{~m} / \mathrm{s}$. 


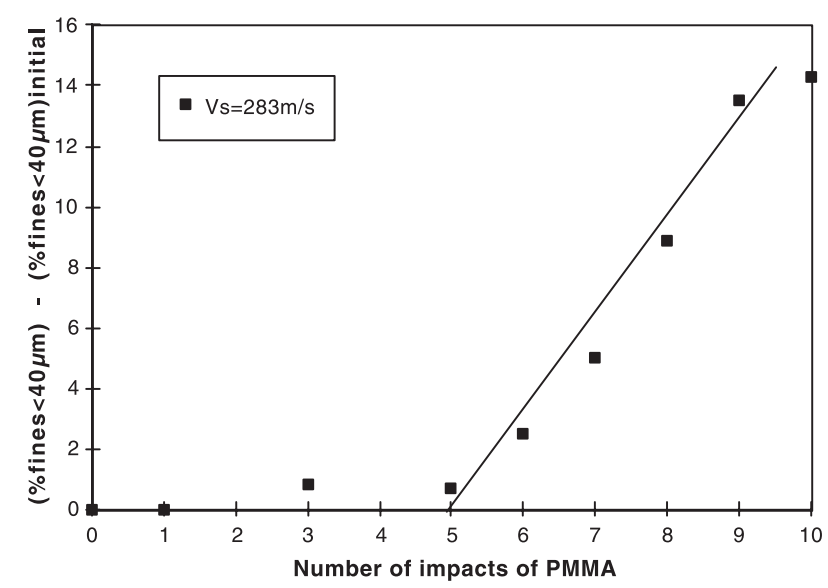

Fig. 14. Multi-impact profile for PMMA at $283 \mathrm{~m} / \mathrm{s}$.

\subsection{Analysis of repeated breakage}

Some authors $[26,27]$ treat their multiple impact results with a first-order rate equation. They fit an exponential decrease of the unbroken fraction of their feed solid with the number of impacts. In our case, that approach did not work very well, which is not surprising as the methodology used here is different: after each impact, the whole sample is reimpacted. According to the relatively low number of points available for hydrargillite (stagnation is observed after two to three impacts), a simpler linear relation fits better. As it has been observed with single impact, the fineness criterion is proportional to the provided kinetic energy. Thus, once again, a linear dependence is looked for between the fraction of solid under $40 \mu \mathrm{m}(\%<40 \mu \mathrm{m})$ and the number of impacts $(N)($ Eq. (3)).

$(\%<40 \mu \mathrm{m})-(\%<40 \mu \mathrm{m})$ initial $=k N$

Figs. 12-14 show for the three studied solids, the evolution of the relative fraction under $40 \mu \mathrm{m}$ with the number of impacts.

For the hydrargillite, the number of points is definitely too small, but for $\mathrm{NaCl}$ and PMMA, the reliability is better. Eq. (3), if validated, leads to the proportional factors $k$ given in Table 5. Furthermore, in Fig. 15, $k$ data are plotted vs. the effective kinetic energy per impact $\left(E_{\mathrm{s}}-E_{\mathrm{so}}\right)$ for $\mathrm{Al}(\mathrm{OH})_{3}$ and $\mathrm{NaCl}$.

Table 5

Proportional factors $k$ from Eq. (3)

\begin{tabular}{lccl}
\hline Solid & $E_{\mathrm{s}}\left(\mathrm{kJ} \mathrm{kg}^{-1}\right)$ & $k(\%$ fines impact & -1 \\
\hline $\mathrm{Al}(\mathrm{OH})_{3}$ & 1.1 & 7.8 & Correlation coefficient \\
& 2.5 & 19.5 & 0.87 \\
& 3.9 & 32.8 & 0.95 \\
& 8.7 & 23.3 & 0.99 \\
& 13.9 & 43.5 & 0.96 \\
$\mathrm{NaCl}$ & 0.2 & 7.0 & 0.91 \\
& 0.3 & 13.7 & 0.94 \\
PMMA & 40 & 3.0 & 0.81 \\
\hline
\end{tabular}

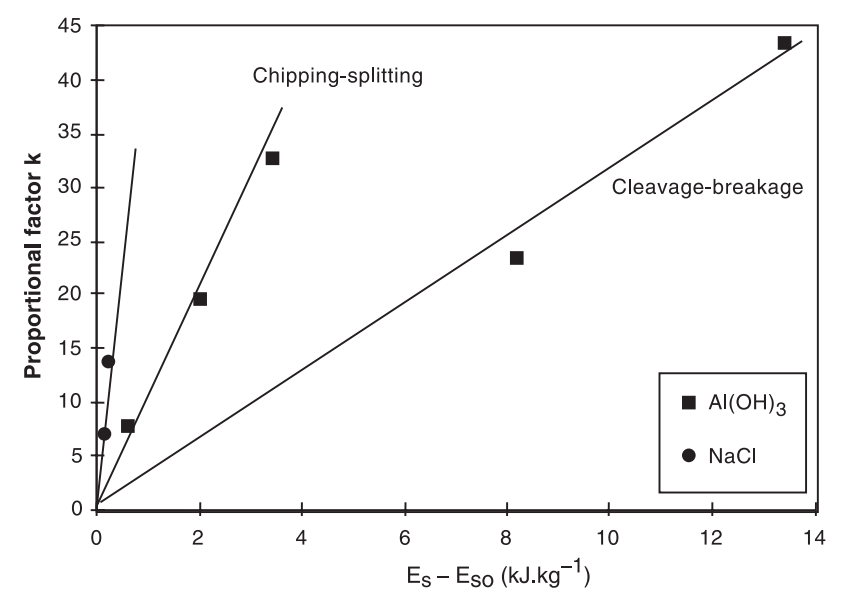

Fig. 15. Multiple impact proportional factor $k$ vs. effective energy per impact.

For hydrargillite, two separate straight lines can be seen. One corresponds to the chipping-splitting region, the other one to the cleavage-breakage regime. As a result, the multiple breakage behaviour of $\mathrm{Al}(\mathrm{OH})_{3}$ is dependant on its breakage regimes, which was already said in Fig. 9.

For $\mathrm{NaCl}$, the two points are appreciably aligned with the origin.

In conclusion, the previous simple approach leads to physically understandable results. So far, the broken fraction after repeated impact is proportional to the number of impacts and the proportional factor depends linearly on the effective grinding energy $\left(E_{\mathrm{s}}-E_{\mathrm{so}}\right)$. Unfortunately, so far, the influence of the mechanical properties is not directly shown in this approach. This is to be done in the future.

\section{Conclusions}

The test rig allows one to characterise the breakage behaviour of any solid at impact on a target. So far three types of behaviour have been found: brittle (glass, polyamide, sand and $\mathrm{NaCl})$, complex $\left(\mathrm{Al}(\mathrm{OH})_{3}\right)$ and ductile (PMMA).

Results of single impacts are in accordance with the literature which indicates a linear dependence of the size reduction ratio on the square of the impact velocity above the attrition threshold. A classification is obtained by means of the change of fineness criteria with energy criteria and with the determination of energy threshold (attrition threshold $V_{\mathrm{so}}$ or $E_{\mathrm{so}}$ ) and grindability parameters (slope $p$ ).

Multiple impact study shows that a solid is not broken similarly if a given energy is provided in one or several impacts. In addition, there is no more size reduction after only three to four impacts for hydrargillite, four for $\mathrm{NaCl}$. Even though PMMA should theoretically have a ductile behaviour, it has been found possible to fragment it by five successive impacts. This may be explained as a result of fatigue. 


\section{Nomenclature}

$a_{\mathrm{s}} \quad$ specific surface area $\left(\mathrm{m}^{2} \mathrm{~kg}^{-1}\right)$

$d_{\mathrm{m}} \quad$ particle arithmetic mean diameter $(\mu \mathrm{m})$

$d_{\mathrm{h}} \quad$ particle harmonic mean diameter $(\mu \mathrm{m})$

$d_{\text {ai }} \quad$ mean sieve size $(\mu \mathrm{m})$

$d_{\mathrm{i}} \quad$ initial mean diameter $(\mu \mathrm{m})$

$d_{\mathrm{f}} \quad$ final mean diameter, after impact $(\mu \mathrm{m})$

$d_{\mathrm{i}} / d_{\mathrm{f}} \quad$ size reduction ratio (-)

$E \quad$ kinetic energy (J)

$E_{\mathrm{s}}=0.5 \rho_{\mathrm{s}} V_{\mathrm{s}}^{2}$ specific kinetic energy $\left(\mathrm{kJ} \mathrm{kg}^{-1}\right)$

$H \quad$ hardness (see Eq. (1)) (Pa)

$k \quad$ proportional factor (see Eq. (3)) (\%fines impact ${ }^{-1}$ )

$K_{\mathrm{c}} \quad$ critical stress intensity factor (see Eq. (1)) $\left(\mathrm{Pa} \mathrm{m}^{1 / 2}\right)$

$l_{\mathrm{u}} \quad$ ultimate size (see Eq. (2)) $(\mu \mathrm{m})$

$N \quad$ number of impact (-)

$p, p_{1}, p_{2}$ slopes, grindability $\left(\mathrm{m}^{2} \mathrm{~kJ}^{-1}\right)$

$T_{\mathrm{v}} \quad$ glass transition temperature $\left({ }^{\circ} \mathrm{C}\right)$

$U_{\mathrm{g}} \quad$ fluid velocity $\left(\mathrm{m} \mathrm{s}^{-1}\right)$

$V_{\mathrm{S}} \quad$ particle velocity $\left(\mathrm{m} \mathrm{s}^{-1}\right)$

$W_{\mathrm{j}}, W_{\mathrm{s}}$ fluid, solid mass flow rate $\left(\mathrm{kg} \mathrm{s}^{-1}\right)$

$x_{\mathrm{i}} \quad$ mass fraction of solid collected on sieve of mean size diameter $d_{\mathrm{ai}}$ (wt.\%)

$Y \quad$ Young's modulus $(\mathrm{Pa})$

$\lambda \quad$ Laitone inertia number (-) [5]: $\lambda=\left(\rho_{\mathrm{s}} d^{2} R e_{\mathrm{s}} C_{\mathrm{d}} U_{\mathrm{g}}\right) /$ $\left(432 \mu_{\mathrm{g}} D\right)$, with $R e_{\mathrm{s}}=$ particulate Reynolds number; $\left.R e_{\mathrm{s}}=\left(U_{\mathrm{g}}-V_{\mathrm{s}}\right) \rho_{\mathrm{g}} d / \mu_{\mathrm{g}}\right)(-) ; C_{\mathrm{d}}=\operatorname{drag} \operatorname{coefficient}(-)$; $\mu_{\mathrm{g}}=$ fluid viscosity (Pa s); $D=$ distance nozzle target $(\mathrm{m})$

$\mu \quad$ mass load ratio $=W_{\mathrm{j}} / W_{\mathrm{s}}(-)$

$\xi \quad$ a fineness criterion $[\xi]$

$\rho_{\mathrm{g}}, \rho_{\mathrm{s}} \quad$ specific gravity for fluid, for solid $\left(\mathrm{kg} \mathrm{m}^{-3}\right)$

$\sigma_{\mathrm{c}} \quad$ critical fracture stress $(\mathrm{Pa})$

$v \quad$ Poisson's ratio $(-)$

c critical threshold

i initial

f final

g gas, fluid

s solid

$0 \quad$ attrition threshold

\section{Acknowledgements}

This research is financially supported by the French National Scientific Research Agency CNRS, the environment and energy control agency ADEME and receives a complementary grant from the International Fine Particle Research Institute (IFPRI).

\section{References}

[1] M.H. Prior, H. Prem, M.J. Rhodes, Size reduction, in: M.J. Rhodes (Ed.), Principles of Powder Technology, Wiley, Chichester, 1990, pp. 227-298 (Section 10).

[2] M. Mebtoul, J.F. Large, P. Guigon, High velocity impact of particles on a target. An experimental study, International Journal of Mineral Processing 44-45 (1996) 77-91.

[3] Militzer, et al., Solid particle velocity measurement, in: O.E. Potter, D.J. Nicklin (Eds.), Fluidization VII, Engineering Foundation, New York, 1992, pp. 763-768.

[4] J. Dodds, C. Frances, P. Guigon, A. Thomas, Investigations into very fine grinding, Kona-Powder and Particle 13 (1995) 113-124.

[5] J.A. Laitone, Aerodynamic effects in the erosion process, Wear 56 (1979) 239-246.

[6] W. Weibull, A statistical theory of the strength of materials, Ingeniörs Vetenskaps Akademien Handligar, Generalstabens Litografiska Anstalts Förlag, Stockholm, 1939, no. 151.

[7] A.A. Griffith, The phenomena of rupture and flow in solids, Philosophical Transactions of the Royal Society of London, Series A 221 (1921) 163-198.

[8] P.H. Shipway, I.M. Hutchings, Attrition of brittle spheres by fracture under compression and impact loading, Powder Technology 76 (1993) 23-30.

[9] H.J. Herrmann, S. Roux, Statistical Models for the Fracture of Disordered Media, North-Holland, 1990, ISBN 0444883568.

[10] L.G. Austin, Approximate calculation of specific fracture energies for grinding, Powder Technology 53 (1987) 145-150.

[11] Y. Kanda, Y. Abe, M. Yamaguchi, C. Endo, A fundamental study of dry and wet grinding from the viewpoint of breaking strength, Powder Technology 56 (1988) 57-62.

[12] S.P. Timoshenko, J.N. Goodier, Theory of elasticity, Engineering Societies Monographs, McGraw-Hill, New York, 1970.

[13] S. Okuda, W. Choi, Grinding characteristics of target type fluid energy mill, Journal of Chemical Engineering of Japan 13 (13) (1980) $219-225$.

[14] Goodfellow catalogue, Goodfellow SARL, Cambridge Science Park, United Kingdom, 1997.

[15] A.U. Neil, J. Bridgwater, Attrition of particulate solids under shear, Powder Technology 80 (1994) 207-219.

[16] S. Okuda, W. Choi, Fracture characteristics of single particle of polymeric materials under impact loading, Journal of Chemical Engineering of Japan 12 (5) (1979) 383-388.

[17] J.T. Hagan, Impossibility of fragmenting small particles: brittleductile transition, Journal of Materials Science Letters 16 (1981) 2909-2911.

[18] K. Kendall, The impossibility of comminuting small particles by compression, Nature 272 (1978, April 20) 710-711.

[19] M. Ghadiri, D.G. Papadopoulos, Impact attrition of particulate solids, IFPRI annual report ARR 16-05, University of Surrey, 1993.

[20] J.T. Hagan, Micromechanics of crack nucleation during indentations, Journal of Materials Science 14 (1979) 2975-2980.

[21] M. Ghadiri, D.G. Papadopoulos, Attrition of particulate solids, IFPRI annual meeting report ARR 16-07, University of Surrey, 1995, June.

[22] G. Jimbo, Q.Q. Zhao, T. Yokoyama, Y. Taniyama, The grinding limit and the negative grinding phenomenon, Proceedings of Second World Congress Particle Technology, Kyoto, Japan, 19-22 September, 1990, pp. $123-128$

[23] R. Hogg, H. Cho, A review of breakage behavior in fine grinding by stirred-media milling, Kona 18 (2000) 9-19.

[24] J.A.S. Cleaver, M. Ghadiri, N. Rolfe, Impact attrition of sodium carbonate monohydrate crystals, Powder Technology 76 (1993) $15-22$.

[25] K. Leschonski, U. Menzel, Experimental investigations on single plate fluid energy milling, Proceedings of First World Conference on Particle Technology, vol. 2, 1988, pp. 297-323.

[26] P.M.M. Vervoorn, L.G. Austin, The analysis of repeated breakage events as an equivalent rate process, Powder Technology 63 (1990) $141-147$.

[27] L.G. Austin, P.M. Trubelja, B. Scarlett, A study of the fracture of pellets fired against a target, Particle \& Particle Systems Characterization 10 (1993) 347-352. 